\title{
Prediction of Surface Roughness and Power in Turning Process Using Response Surface Method and ANN
}

\author{
Amanda ALJINOVIĆ*, Boženko BILIĆ, Nikola GJELDUM, Marko MLADINEO
}

\begin{abstract}
This paper examines the influence of three cutting parameters (cutting speed, cutting depth and feed rate) on surface roughness and power in the longitudinal turning process of aluminium alloy. For the analysis of data gathered by experiments, two methods for prediction of responses were employed, namely Response Surface Methodology (RSM) and Artificial Neural Network (ANN). The research has shown that the ANN gives a better prediction of surface roughness than the RSM. In the modelling of the power, the average error value obtained by the ANN does not differ significantly from its value obtained by the RSM. This research is conducted to reveal the rigidity of the machine tool in order to select an appropriate spindle motor for retrofit purpose. The unexpected surface roughness and the error between the experimental and predicted values show that the obtained models are, in most cases, not adequate to predict surface roughness when the power is greater than a given limit. Therefore, the servo motor with smaller power than the original motor is selected which is cost-effective and it will not cause inappropriate strong vibrations that lead to the unexpected surface roughness and excessive noise inside the Learning Factory environment in which the machine tool is used.
\end{abstract}

Keywords: artificial neural network (ANN); power; response surface method (RSM); surface roughness

\section{INTRODUCTION}

Turning is one of extensively and most frequently used material removal processes in industrial application. The obtained surface roughness of machined part remains the most relevant parameter in terms of assessing workpiece quality, as is geometrical sizes and their tolerance since it has a great influence on machined parts performances. This indicator of surface quality represents one of the most frequently specified customers' demands. The surface roughness is influenced by several parameters among which are technological processing parameters. On the other side, a small number of researches have focused on the power consumption of the machine during turning [1]. Reduction of machine power will lead to higher energysaving and thus to higher machine efficiency and decrease in total processing cost.

The knowledge of the impact of these parameters on surface roughness requires the development of a predictive mathematical model in order to ensure more efficient and less expensive process. Significant researches have focused on the usage of predictive modelling approaches for different machining processes in order to determine the optimal cutting conditions or relationships between independent cutting parameters on performance measures. One of the most extensively used approaches is the response surface methodology (RSM) because of its ability to provide a huge amount of information from a small number of experiments. Its major leverage lays in the ability to offer information about the influence of independent parameters on performance characteristics [2]. Due to its weak behaviour when confronted with nonlinear phenomena [3] and because of the constraint that the input parameters must be entered and specified according to the experimental plan [4] the various authors explored some other approaches. Between them, the artificial neural network (ANN) gained much acknowledgement among researchers due to its efficiency, simplicity and more accuracy in comparison to the other techniques, especially when it is about non-linear systems, as well as for modelling factor in machining processes $[3,5]$.
Paper [6] investigated the cutting parameters of Al-Cu TiC MMCs on surface roughness (the average roughness $R a$, the average maximum height of the profile $R z$, and maximum peak to valley height of the profile $R t$ ) during turning operations by employing the ANN approach. They conclude that the ANN is a precise technology for prediction of these responses.

Authors in [1] tested the machining parameters, i.e. cutting speed, feed rate and depth of cut using the RSM and genetic algorithm (GA) to obtain minimum power consumption $(P)$ as a function of mentioned factors for AISI 1045 steel during turning. The ANOVA analysis revealed that the power is largely influenced by the depth of cut which explains the contribution of $61,71 \%$. The next significant factor is the cutting speed with the contribution of $16,4 \%$ and the last one is the feed rate with $12,85 \%$. The optimal power consumption was found after the 34 generations applying the GA. On the other side, research [2] examined the influence of machining parameters on power consumption $(P)$ and surface roughness $(R a)$ during the turning of AISI 1045 steel. The authors used both grey relation analysis and RSM in order to develop a multiobjective predictive model for optimization of output parameters. The obtained results show that the feed rate significantly affects the outputs with the contribution of $61,66 \%$ followed by the depth of cut and finally the cutting speed.

In another paper [7] authors evaluated the influence of cutting parameters on surface roughness $(R a)$, tangential cutting force $\left(F_{z}\right)$ and cutting power $\left(P_{c}\right)$ during the turning of POM C polymer implementing the ANN and RSM approaches. The obtained results reveal that the feed rate is the most influential parameter on $R a$ with a contribution of $66,41 \%$ followed by the depth of cut and cutting speed. Besides, the depth of cut was found to be the most influential factor on $F_{z}$ and $P_{c}$. The second influential factor for $F_{z}$ and $P_{c}$ is the feed rate. Furthermore, according to the determination coefficient $\left(R^{2}\right)$ of the developed mathematical models, ANN was found to be robustness and more reliable method than RSM.

In the same way, comparative study [8] is taken in terms of surface roughness $(R a)$, the tangential cutting 
force $\left(F_{z}\right)$, the cutting power $\left(P_{c}\right)$ and the material removal rate $(M R R)$ in the turning of EN-GJL-250 cast iron using coated and uncoated silicon nitride ceramics. The weakest influence on surface roughness is exerted by the cutting depth and the strongest by the feed rate. Additionally, based on the ANOVA results, at the first place for all other responses $\left(F_{z}, P_{c}\right.$ and $\left.M R R\right)$ the cutting depth developed the greatest influence. The feed rate comes in the second position, while the cutting speed is in the third position. The comparative study between ANN and RSM shows that the ANN technique is more efficient in terms of predictive capabilities. Moreover, in the paper [9] the authors show that the feed rate is the most significant factor followed by the depth of cut and the cutting speed as the least significant factor when obtaining minimal power consumption for AISI $6061 \mathrm{~T} 6$ aluminium during turning. They also show that the feed rate is the most significant factor for surface roughness. This differences for power may be due to the different type of workpiece material.

The investigation conducted by [10] investigates the surface roughness and tool wear during the turning of $\mathrm{Al} / \mathrm{SiCP}$ MMC. The authors used RSM and ANN to develop predictive mathematical models and to compare their predictive capabilities. They concluded that the surface roughness is highly influenced by the feed rate. On the other side, tool wear is influenced by feed rate and cutting speed. They also concluded that the ANN has better prediction accuracy than RSM for surface roughness and for tool wear calculating the average of individual accuracy on confirmation data set. However, research presented in [11] examined the influence of machining parameters on Al 7075/10SiCp and Al 7075 Hybrid Composite. They applied RSM and ANN, and found out that the feed rate had the most dominating effect on surface roughness $(R a)$, followed by the approach angle and cutting speed in both cases. Furthermore, they concluded that the ANN mathematical prediction model generated more errors than the RSM ones.

Similarly, in the literature it can be found that the researchers have implemented the RSM or ANN to different processes in order to gain a predictive mathematical model for required responses. For example, [12] compared the prediction accuracy of least square approximation method and RSM method for prediction of surface roughness of aluminium during end milling. They concluded that the RSM provided a better prediction of surface roughness. Paper [13] represents the comparative study that used different neural networks to estimate the process parameters during grinding.

In accordance with the above-mentioned studies, it can be noted that one of their missions is to identify the most accurate and robust modelling method that will be able to provide a precise mathematical prediction model that can be further used for the optimization.

In the present work, firstly, an attempt was made to investigate the effect of cutting parameters (cutting speed, cutting depth and feed rate) on the surface roughness and power consumption during the turning of aluminium alloy EN AW 2011 T8. Secondly, the response RSM and ANN were adopted to develop a mathematical prediction model. Additionally, the predictive capabilities of two mentioned methods were compared in terms of better coefficient of determination $\left(R^{2}\right)$ and mean absolute percentage error
(MAPE). This study is conducted on a conventional lathe machine which is located in the laboratory for industrial engineering at FESB where the Learning Factory (LF) is being developed. LF presents a simulation of a real factory through specialized equipment. It implies the establishment of "living lab" for research, development, demonstration and knowledge transfer to the economy [14]. Also, this relatively small machine tool, compared to the most ones used in industry, is used to produce many parts for the development needs of the LF. Its usage in the laboratory environment, especially if the laboratory is occupied by students and industrial employees, is not convenient. High noise level, high vibration and big deformation of machined parts that were measured to appear at a higher level of power during turning, disable this machine tool to be used in the demonstrated and afterwards analysed production process. Besides that, LF is continuously evolving to Smart factory concept, using different equipment and approaches related to Industry 4.0 paradigm. Therefore, it is decided to retrofit this conventional machine tool, with servo motors and sensors in order to demonstrate the abilities of computer numerically controlled (CNC) machining on one side and to enable repetitive production processes monitored by Industry 4.0 related equipment on the other side. In that case, both simulation of enhanced real factory process and demonstration of emerging technologies, like Industry 4.0 related equipment, could be enabled, which are the main goals of the LF concept.

According to [9], optimizing the existing processes means lower investment needed and user acceptance, better than making drastic changes. So, it is convenient to examine the operating range of this lathe primarily for its retrofit equipment selection in order to decrease the investment costs, cutting process costs, increase the quality of machined parts and to define the maximum input factor values at which the surface roughness is still acceptable. After the testing of prediction capability of chosen techniques, the conclusion about retrofitting of the present machine will be given.

Prior to retrofit activities, the research presented in this paper will reveal maximum power that can be applied for original rigidity of the machine tool, on which surface roughness and dimension accuracy are still acceptable.

On the one hand, in order to precisely define, as close as possible, the upper power boundary limit above which vibration and deformations of supporting parts significantly increase surface roughness and thus reduce dimensional accuracy, the two modelling methods will be used, RSM and ANN. On the other hand, those methods will be compared in order to detect which one gives a more precise prediction model for turning of EN AW 2011 T8.

\section{EXPERIMENTAL SETTINGS}

Experimental research was performed in dry cutting conditions using a conventional lathe machine, with the power of electric motor rated $1100 \mathrm{~W}$ and a maximum spindle speed of $2000 \mathrm{rpm}$. The lathe has six constant spindle speeds which can be adjusted with the disposition of the transmission belt ratio that is connected with the main spindle. Values between those six spindle speeds cannot be easily adapted and therefore only one spindle 
speed, $460 \mathrm{rpm}$, is used for experimentation. The tool holder PCLNR 2020K 12 along with CNMG 432-TF insert is used. The material used for the experiments is a bar of $55 \mathrm{~mm}$ in diameter, made of aluminium alloy EN AW 2011 T8.

Cutting parameters: cutting speed $\left(v_{c}\right)$, feed rate $(f)$ and cutting depth $\left(a_{p}\right)$ were considered as input parameters in the experimental plan.

In order to examine the operating range of the conventional lathe machine, preliminary experiments were performed on the same bar. Among others, an experimental study was conducted on 3 different diameters $54,6 \mathrm{~mm}$, $40,7 \mathrm{~mm}$ and $30 \mathrm{~m}$. Since the spindle speed is a constant value, cutting speed depends only on changes in cutting process diameter.

Ranges of cutting parameters were selected according to the machine characteristics and preliminary experiments. Within the experiments, most of the feed rates that the machine could use were tested, while the depth of cut was examined in the range of $0,5-3 \mathrm{~mm}$. For each diameter, i.e. cutting speed, through the preliminary examination, maximum feed rates and cutting depths were determined. As a result, the operating range of the machine was defined and is depicted in Fig. 1.

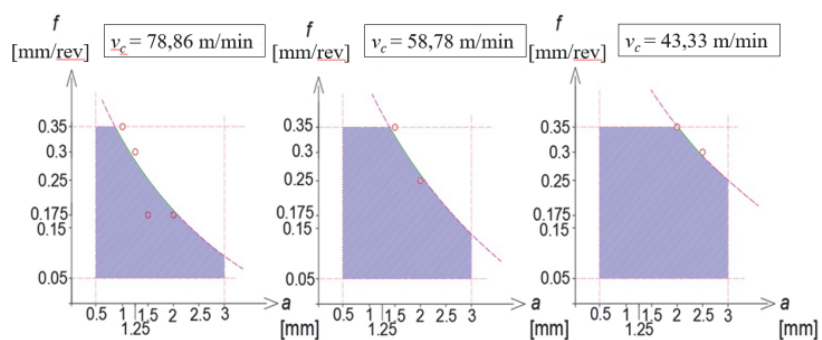

Figure 1 Obtained operation range of conventional lathe machine

Since the lathe has a tendency to block during its overload, it is necessary to carefully specify the upper bounds of the cutting parameters. Taking into account its constraints, as well as the need to examine the influence of the marginal areas with a small number of experiments, the rotational central composite design (RCCD) was used.

RCCD of experiments $2^{3}$ was adopted. Rotatability of $\mathrm{CCD}$ is obtained by adding the points to the central compositional plan at a distance $\alpha= \pm 1,682$ from the central axes. The required number of experimental points for RCCD model is calculated according to the expression:

$$
N=2^{k}+2 k+m_{0}=m_{k}+m_{\alpha}+m_{0}
$$

where $k$ is the number of parameters in the experiment.

The three-factorial RCCD of the experiment demands a total of 20 experiments whose combination of parameters was generated using the software Design Expert. From a total of 20 observed experiments, 8 experiments refer to the base part of the rotatable plan ( 3 factors on 2 levels, $2^{k}=$ $2^{3}$ ), 6 experiments are symmetrically positioned on the central axes $\left(m_{\alpha}\right)$ and 6 experiments refer to the repeat point in the centre of the plan of the experiment $\left(m_{0}\right)$.

Surfest SJ 301 instrument was adopted to measure the surface roughness $(R a)$. For each experiment, $R a$ was measured at three different locations on the workpiece, the mean value was computed and used for analysis. For power $(P)$ measuring, a calibrated instrument based on the ATMEGA328P microchip was used. Taking into account the lathe constraints, as well as the obtained operation range, levels of cutting parameters for the experiments were defined. Parameter levels were entered in the software and the experimental plan was gained. The plan is shown in Tab. 1, together with the corresponding response values for each experiment.

Table 1 Results of the conducted experiments

\begin{tabular}{|c|c|c|c|c|c|}
\hline \multirow{2}{*}{$\begin{array}{c}\text { Exp. } \\
\text { No. }\end{array}$} & \multicolumn{3}{|c}{ Input parameters } & \multicolumn{2}{c|}{ Measured values } \\
\cline { 2 - 6 } & $v_{c} / \mathrm{m} / \mathrm{min}$ & $a_{p} / \mathrm{mm}$ & $f / \mathrm{mm} / \mathrm{rev}$ & $R a / \mu \mathrm{m}$ & $P / \mathrm{W}$ \\
\hline 1 & 51 & 1,25 & 0,175 & 1,2 & 515 \\
\hline 2 & 41 & 0,75 & 0,25 & 2,08 & 394 \\
\hline 3 & 41 & 0,75 & 0,1 & 1 & 367 \\
\hline 4 & 51 & 1,25 & 0,175 & 1,2 & 515 \\
\hline 5 & 41 & 1,75 & 0,25 & 2,42 & 538 \\
\hline 6 & 51 & 1,25 & 0,175 & 1,07 & 515 \\
\hline 7 & 51 & 1,25 & 0,175 & 1,07 & 515 \\
\hline 8 & 51 & 1,25 & 0,175 & 1,29 & 515 \\
\hline 9 & 61 & 0,75 & 0,1 & 1,35 & 386 \\
\hline 10 & 51 & 2,09 & 0,175 & 1,76 & 639 \\
\hline 11 & 67,82 & 1,25 & 0,175 & 1,51 & 616 \\
\hline 12 & 41 & 1,75 & 0,1 & 0,91 & 432 \\
\hline 13 & 34,2 & 1,25 & 0,175 & 2,04 & 479 \\
\hline 14 & 51 & 1,25 & 0,049 & 0,96 & 396 \\
\hline 15 & 61 & 1,75 & 0,25 & 1,18 & 755 \\
\hline 16 & 51 & 1,25 & 0,175 & 1,29 & 511 \\
\hline 17 & 61 & 1,75 & 0,1 & 1,67 & 503 \\
\hline 18 & 51 & 1,25 & 0,301 & 2,85 & 767 \\
\hline 19 & 51 & 0,41 & 0,175 & 0,75 & 392 \\
\hline 20 & 61 & 0,75 & 0,25 & 2,46 & 435 \\
\hline
\end{tabular}

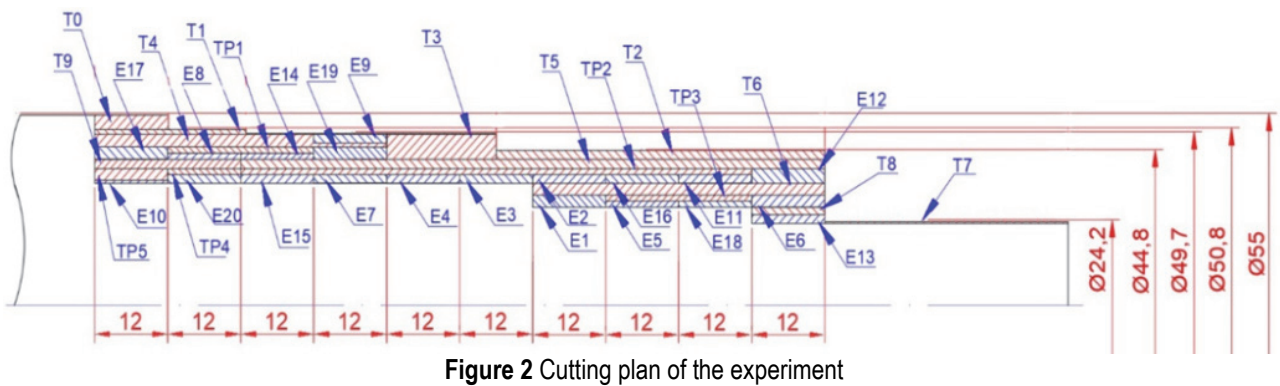

In order to gain the generated input parameter values for experiments, it was necessary to achieve appropriate cutting speeds. That was accomplished by calculating the needed diameters with the note that spindle speed is predefined and amounts $460 \mathrm{rpm}$. Cutting plan of experiments was constructed and it is presented in Fig. 2. Following preliminary experiments, the cutting plan was designed in order to get the minimum loss of material and the minimum number of gear changes for feed rate setup. Also, it was important that each turning length is $12 \mathrm{~mm}$ 
because that value is required for the surface roughness measuring. According to Fig. 2. the values marked with E1 to E20 label refer to the experiments obtained by the plan of experiment. They are shown in Tab. 1. Values marked with $\mathrm{T} 0$ to $\mathrm{T} 8$ label are turning passes needed for material removal in order to obtain the required diameter for experiments, while the values marked with TP1 to TP5 are passes between two similar experiments. Experiments in $\mathrm{T}$ and TP groups will later be used as an additional experiment required for testing and validation of models prediction.

\section{RESPONSE SURFACE METHOD}

The response surface method (RSM) is a mathematical and statistical technique used for the determination of the functional relationship between various process parameters and responses [15]. RCCD models the response using the empirical second-order polynomial regression model called the quadratic model:

$$
y=b_{0}+\sum_{i=0}^{k} b_{i} * X_{i}+\sum_{1 \leq i<j}^{k} b_{i j} * X_{i} * X_{j}+\sum_{i=1}^{k} b_{i i} * X_{i}^{2}
$$

where $y$ is the estimated response value, $b_{0}, b_{i}, \mathrm{~b}_{i i}$ and $b_{i j}$ are the regression coefficients, and $X_{i}$ and $X_{j}$ are the coded values of input parameters. The second-order response surface equations have been fitted using Design Expert software for all response variables, $R a$ and $P$. The quadratic model in terms of the actual values of the independent variables and their interactions is given in the following regression equations:

$$
\begin{aligned}
& R a=1,07627-0,113187 \cdot v_{c}+2,21084 \cdot a_{p}+12,56750 \cdot f- \\
& -0,030250 \cdot v_{c} \cdot a_{p}-0,328333 \cdot v_{c} \cdot f-3,9000 \cdot a_{p} \\
& \cdot f+0,001998 \cdot v_{c}^{2}+0,063674 \cdot a_{p}^{2}+43,68500 \cdot f^{2} \\
& P=592,89712-3,82901 \cdot v_{c}-147,79355 \cdot a_{p}-2076,46654 \cdot \\
& \cdot f+5,70 \cdot v_{c} \cdot a_{p}+28,0 \cdot v_{c} \cdot f+940,0 \cdot a_{p} \cdot f- \\
& -0,038831 \cdot v_{c}^{2}-60,78704 \cdot a_{p}^{2}+1446,71351 \cdot f^{2}
\end{aligned}
$$

Statistical analysis of data shows that the quadratic model is adequate for a description of surface roughness and power, and therefore can be used for further analysis. From Eq. (3) and Eq. (4) it can be seen that the factor with the highest value of coefficient has the most dominant effect on the response. Determination coefficient $R$ squared, which is defined as the ratio of the explained variation to the total variation [16] can be used for the model quality evaluation. For $R a$ and $P$, it amounts, respectively, to 0,8049 and 0,8768 . High $R$-squared indicates that the predicted response values based on the models are in good agreement with the experimental data.

Analysis of Variance (ANOVA) test was performed to identify the significance of the cutting parameters on responses. According to ANOVA and obtained F-value, which is used to check the adequacy of the model, the model is significant for both responses. The statistically significant model parameter that has the highest influence on $R a$ is a feed rate $f$ (as $p$-value $<0.5$ ), with the $55,8 \%$ contribution of the total variation. For the remaining parameters, the $p$-value is more than the confidence level. According to the percentage of influence of each parameter, they have a negligible contribution on the $R a$ of the turned surface. This conclusion differs from the previously mentioned researches.

The $R a$ in terms of the response variable can be explained through three-dimensional surface plots. These plots are shown in Fig. 3, Fig. 4 and Fig. 5.

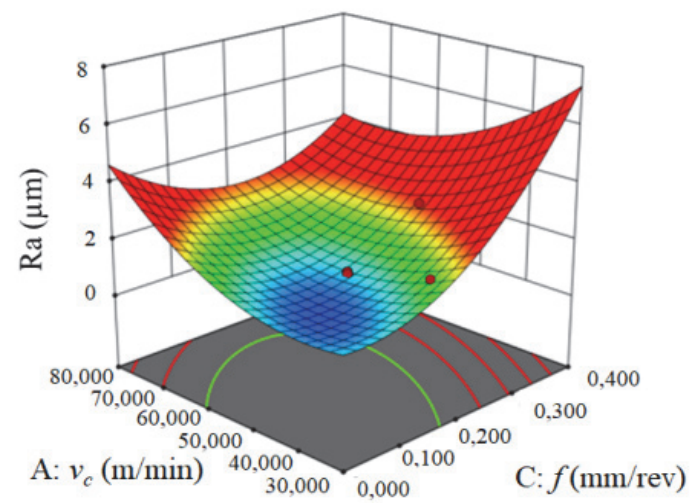

Figure 3 Influence of cutting speed and feed rate on surface roughness for the constant depth of cut of $1,25 \mathrm{~mm}$

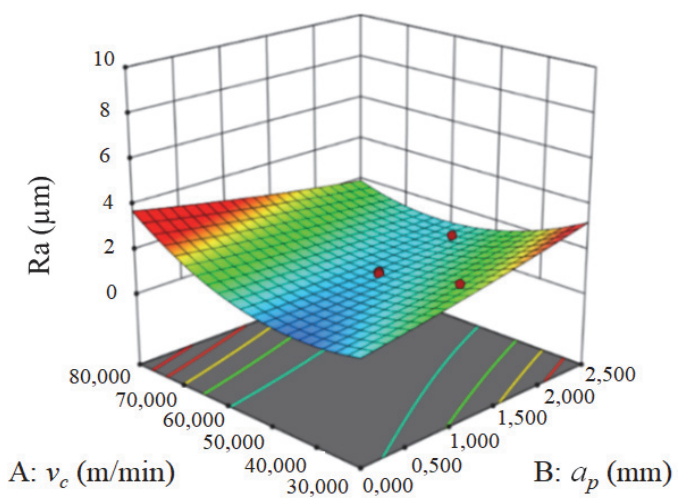

Figure 4 Influence of cutting speed and depth of cut on surface roughness for the constant feed rate of $0,175 \mathrm{~mm} / \mathrm{rev}$

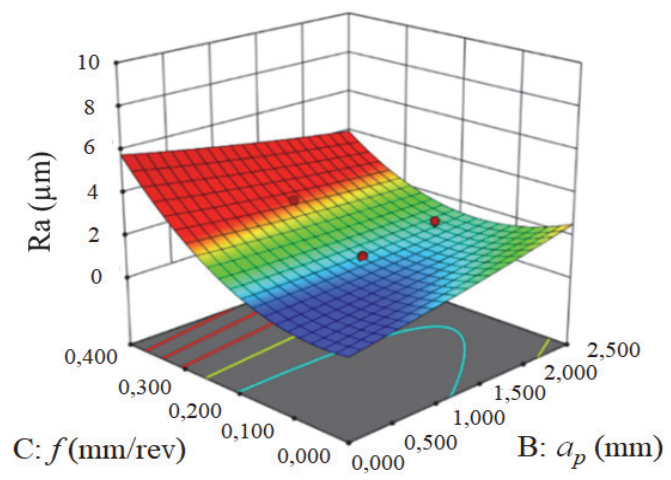

Figure 5 Influence of feed rate and depth of cut on surface roughness for the constant cutting speed of $51 \mathrm{~m} / \mathrm{min}$

Response surfaces for both responses are gained by varying two different parameters, while the third parameter is kept at a mean value. With the decrease of the feed rate, surface roughness decreases and vice versa. Increasing feed rate leads to the rapid tool movements which deteriorate the quality of the machined surface, as well as 
to the vibration on the machine tool and generation of more heat and therefore contributes to the higher surface roughness $[10,17,18]$.

ANOVA for $P$ indicates that all three parameters are statistically significant for the model, as it was confirmed in the research [9], but the evaluation of the significance of cutting parameters differs. In this case, the depth of cut $\left(a_{p}\right)$ with $38,6 \%$ and feed rate $(f)$ with $38,4 \%$ contribution of the total variation, are the most significant factors. Results gained by response surface method for $P$ are presented in Fig. 6, Fig. 7 and Fig. 8. Power increases with the increase in depth of cut and feed rate due to increased crosssectional chip volume removed.

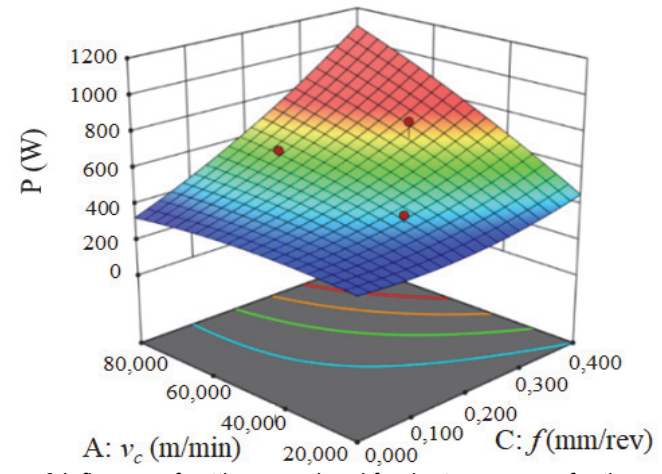

Figure 6 Influence of cutting speed and feed rate on power for the constant depth of cut of $1,25 \mathrm{~mm}$

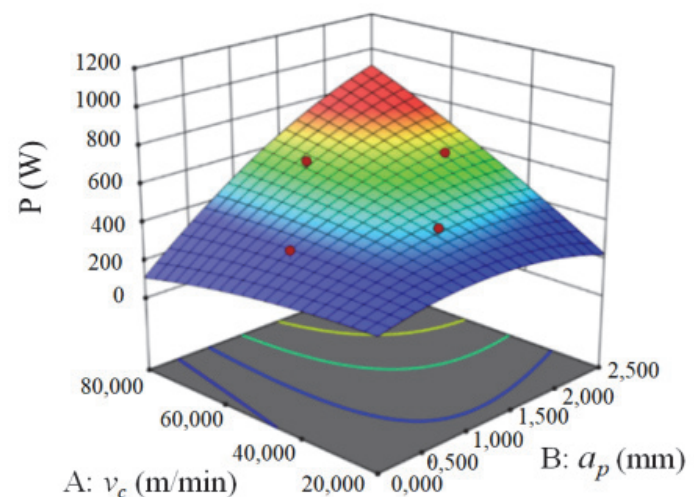

Figure 7 Influence of cutting speed and depth of cut on power for the constant feed rate of $0,175 \mathrm{~mm} / \mathrm{rev}$

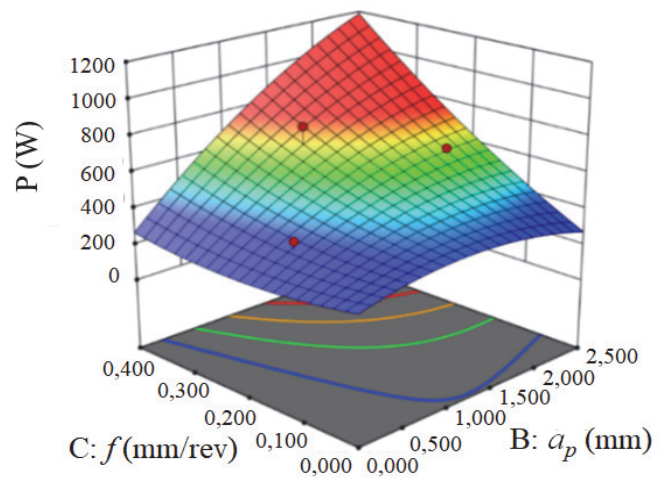

Figure 8 Influence of feed rate and depth of cut on power for the constant cutting speed of $51 \mathrm{~m} / \mathrm{min}$

\section{ARTIFICIAL NEURAL NETWORK}

Artificial neural network (ANN) is a computational derived parallel data processor inspired by the work of the brain. Its knowledge is achieved through the learning process. Interconnection strengths called weight is the place where the processing ability of the network is stored. The learning data set consists of input $p$-dimensional vectors $\mathrm{x}$ and corresponding output 1-dimensional vectors $\mathrm{y}$ [19]. The learning process can be defined as an iterative process of successive improvement of input parameters of the network, based on the minimization of the function of error between the desired network output and the known input-output combinations of sets $[19,20]$. As goal function when minimizing the error of system responses, the current value of the sum of squares error in step $h$ is usually used:

$$
E(h)=\frac{1}{2} \sum_{l} e_{l}^{2}(h)
$$

where $l$ presents output neuron with the known response, $e_{l}(h)$ is the error in learning, it is equal to the difference between desired and obtained response $l$ at step $h$.

The typical ANN network model consists of three layers that are interconnected. The input layer transfers the input variables to neurons in the hidden layer. The hidden layer receives and processes information of the input layer, while the output layer gives the system response. Each layer contains single or multiple neurons, depending on the problem definition. In order to imitate the nonlinear function, the network needs a neuron activation function. This transfer-activation function determines the moment of launching the impulse to the neuron network and it can be linear or nonlinear [21]. Guidelines or algorithms to select the proper number of neurons do not exist. The number of neurons that gives the lowest mean absolute percentage error is accomplished by optimizing [22].

After a number of trials, it was found that the neural network structure 3-3-1, designed using Matlab, Neural Network Toolbox leads to the best results. Structure 3-3-1 means that the ANN consisting of three input neurons stands for three cutting parameters, one hidden layer with three neurons with the nonlinear bipolar sigmoidal activation function of the neuron and one output neuron (for each analysed response) with the linear activation function.

Afterwards, the selected model was trained with the back propagation Quasi-Newton-Broyden-FletcherGoldfarb-Shanno algorithm. To accomplish this task, 15 of total 24 experiments were employed in the training process, while the remaining 9 experiments were employed for testing and validation. Differences between measured and network predicted response values represent the neural network measure of agreement. In the literature, there are several different indicators of the effectiveness of training of the neural network and its ability to predict correct values for unseen data set. One of the most commonly used is the Pearson coefficient of correlation $R$ [22]. Its value lies in the interval between 0 and 1 . The aim is to get $R$ value as much close to the ideal value, i.e. close or equal to 1 . The $R$-values of 0,90211 and 0,96125 were obtained for the training of surface roughness and power neural network models. These values indicate that the models are representative and with the same, 90,21\% (for $R a$ ), i.e. $96,12 \%$ (for $P$ ) were interpreted. 
The graphical representation of the response surface of observed values by applying the neural network is depicted from Fig. 9 to Fig. 14. Two parameters are varying, while the third one is kept at a middle level.

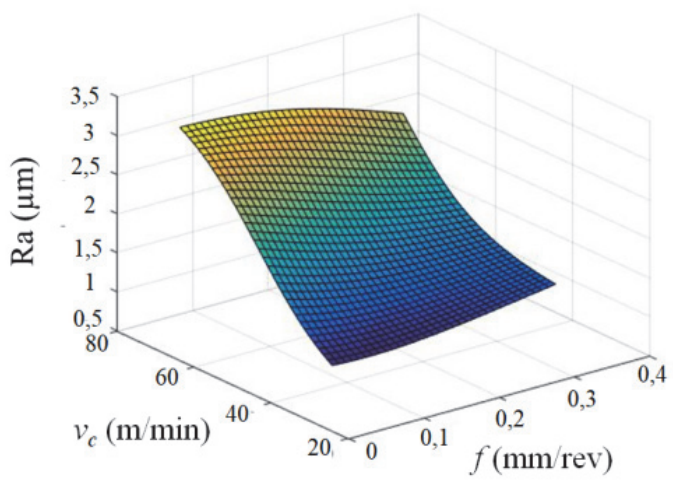

Figure 9 Influence of cutting speed and feed rate on surface roughness for the constant depth of cut of $1,25 \mathrm{~mm}$

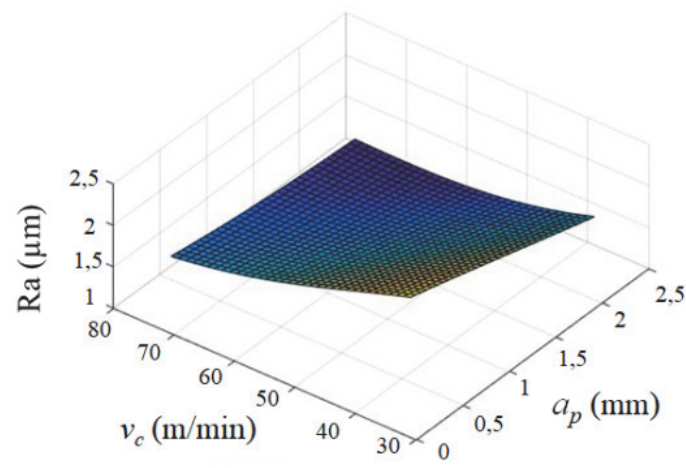

Figure 10 Influence of cutting speed and depth of cut on surface roughness for the constant feed rate of $0,175 \mathrm{~mm} / \mathrm{rev}$

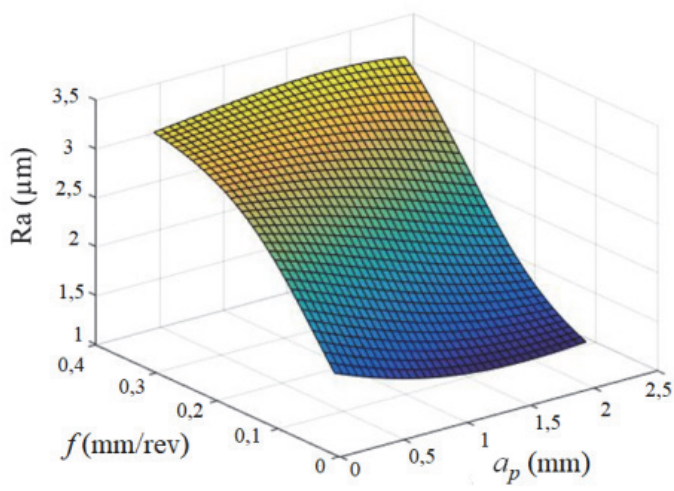

Figure 11 Influence of feed rate and depth of cut on surface roughness for constant cutting speed of $51 \mathrm{~m} / \mathrm{min}$

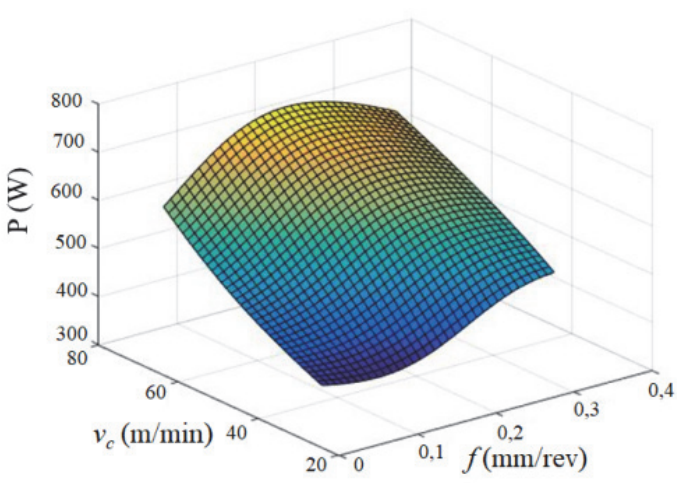

Figure 12 Influence of cutting speed and feed rate on power for the constant depth of cut of $1,25 \mathrm{~mm}$
Fig. 9, Fig. 10 and Fig. 11 are related to Ra. These graphs imply that the $f$ appears as a dominant factor for $R a$. The remaining two parameters, $v_{c}$ and $a_{p}$, have an influence on $R a$, but their influence is negligible in comparison to the $f$. Equal conclusions like in the RSM were adopted.

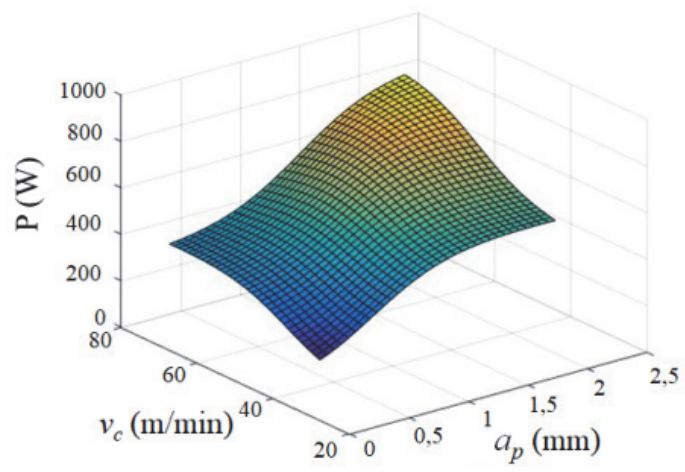

Figure 13 Influence of cutting speed and depth of cut on power for the constant feed rate of $0,175 \mathrm{~mm} / \mathrm{rev}$

Fig. 12, Fig. 13 and Fig. 14 show the response surfaces for $P$. As it can be deduced from these figures, the $a_{p}$ has the dominant influence, thence following $v_{c}$ and $f$. The influence of input parameters on $P$ differs from the results gathered by the response surface method.

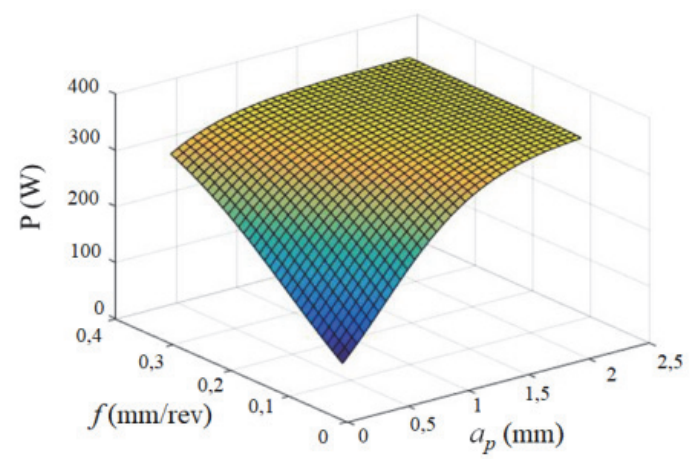

Figure 14 Influence of feed rate and depth of cut on power for the constant cutting speed of $51 \mathrm{~m} / \mathrm{min}$

\section{RESULTS AND ANALYSIS}

In the present study, the predictive models developed by RSM and ANN were compared in order to properly evaluate their prediction abilities. Their capabilities are compared on the basis of the coefficient of determination $\left(R^{2}\right)$ and mean absolute percentage error (MAPE) for surface roughness and power. MAPE is calculated by the formula given in [9] and it includes the absolute percentage error (APE) from all conducted experiments (total of 24). Tab. 2 contains a comparison between the experimental values versus predictive values obtained with RSM and ANN, as well as the associated APE values for analysed responses $(R a$ and $P)$.

Despite the fact that the $R^{2}$ for surface roughness for $\operatorname{RSM}\left(R^{2}=0,8049\right)$ and ANN $\left(R^{2}=0,8138\right)$ model is relatively close, the insight to APE shows that the predictive ability of these two methods differs depending on the runs input parameters while the final MAPE value for surface roughness shows the difference in prediction capability of around $11 \%$ in benefit of ANN. The obtained 
results indicate that with the same number of experiments ANN outperforms prediction ability of RSM.

The comparison between $R^{2}$ coefficient for power when using $\operatorname{RSM}\left(R^{2}=0,8768\right)$ and $\mathrm{ANN}\left(R^{2}=0,924\right)$ indicates that the ANN model is better in the prediction of the response, but those results are conflicting when it is about MAPE values where RSM show smaller relative error than ANN.

Both methods, in some runs, performed well and offered stable responses in predicting the combined interaction of cutting parameters with respect to the experimental results, especially for the $P$. But, as it can be seen from the results, the error between experimental results and results gained by methods for the $R a$ is increasing with the higher values of cutting speed and feed rate, especially when they are followed with the higher values of $P$. It means that obtained models are not adequate to predict surface roughness when the power is greater than approximately $570 \mathrm{~W}$ due to the vibration and the deformation of machined elements that result with the high surface roughness.

Table 2 Testing the capability of all models in predictions of surface roughness and driving power

\begin{tabular}{|c|c|c|c|c|c|c|c|c|c|c|c|c|}
\hline \multicolumn{3}{|c|}{ Input parameters } & \multicolumn{5}{|c|}{ Surface roughness } & \multicolumn{5}{|c|}{ Driving power } \\
\hline$v_{c} / \mathrm{m} / \mathrm{min}$ & $a_{p} / \mathrm{mm}$ & $f / \mathrm{mm} / \mathrm{rev}$ & $\begin{array}{c}\text { Exp. } R a \\
\quad / \mu \mathrm{m}\end{array}$ & $\begin{array}{c}\text { RSM } \\
R a / \\
\mu \mathrm{m}\end{array}$ & $\begin{array}{c}\mathrm{ANN} \\
R a / \\
\mu \mathrm{m}\end{array}$ & $\begin{array}{c}\text { Relative } \\
\text { error } \\
\text { RSM / \% }\end{array}$ & $\begin{array}{c}\text { Relative } \\
\text { error } \\
\text { ANN / \% }\end{array}$ & $\begin{array}{l}\text { Exp. } \\
P / \mathrm{W}\end{array}$ & $\begin{array}{l}\text { RSM } \\
P / \mathrm{W}\end{array}$ & $\begin{array}{l}\text { ANN } \\
P / \mathrm{W}\end{array}$ & $\begin{array}{c}\text { Relative } \\
\text { error } \\
\text { RSM / \% }\end{array}$ & $\begin{array}{c}\text { Relative } \\
\text { error } \\
\text { ANN / \% }\end{array}$ \\
\hline 73,38 & 2,1 & 0,075 & 1,29 & 2,56 & 1,28 & 98,28 & 0,67 & 598 & 557,29 & 758,22 & 6,81 & 26,79 \\
\hline 61 & 1,285 & 0,25 & 1,89 & 1,79 & 1,91 & 5,1 & 1,23 & 650 & 671,6 & 687,86 & 3,32 & 5,82 \\
\hline 69,09 & 1,87 & 0,125 & 1,22 & 1,75 & 1,29 & 43,30 & 5,81 & 688 & 615,05 & 745,76 & 10,60 & 8,40 \\
\hline 61 & 1,87 & 0,088 & 0,72 & 1,55 & 1,16 & 115,63 & 61,36 & 573 & 509,55 & 639,01 & 11,07 & 11,52 \\
\hline 67,82 & 1,25 & 0,175 & 1,51 & 1,67 & 1,44 & 10,89 & 4,95 & 616 & 576,91 & 607,31 & 6,35 & 1,41 \\
\hline 66,05 & 1,855 & 0,088 & 1,39 & 1,83 & 1,21 & 31,65 & 12,73 & 683 & 530,32 & 687,68 & 22,35 & 0,69 \\
\hline 61 & 1,75 & 0,25 & 1,18 & 1,60 & 1,78 & 35,60 & 51,04 & 755 & 788,04 & 782,58 & 4,38 & 3,65 \\
\hline 61 & 0,75 & 0,25 & 2,46 & 2,05 & 2,09 & 16,66 & 15,21 & 435 & 505,12 & 491,46 & 16,12 & 12,98 \\
\hline 57,04 & 1,37 & 0,175 & 1,31 & 1,23 & 1,45 & 6,12 & 10,46 & 686 & 562,79 & 626,46 & 17,96 & 8,68 \\
\hline 51 & 2,09 & 0,175 & 1,76 & 1,36 & 1,36 & 22,99 & 22,89 & 639 & 604,41 & 611,59 & 5,41 & 4,29 \\
\hline 51 & 1,25 & 0,301 & 2,85 & 2,67 & 2,61 & 6,38 & 8,58 & 767 & 669,85 & 698,51 & 12,67 & 8,93 \\
\hline 51 & 1,25 & 0,049 & 0,96 & 1,10 & 1,01 & 14,22 & 5,23 & 396 & 409,55 & 392,82 & 3,42 & 0,80 \\
\hline 51 & 1,25 & 0,175 & 1,2 & 1,19 & 1,52 & 0,93 & 26,93 & 515 & 516,73 & 552,48 & 0,34 & 7,28 \\
\hline 46,05 & 1,715 & 0,15 & 1 & 1,29 & 1,32 & 28,77 & 31,91 & 515 & 508,42 & 543,55 & 1,28 & 5,54 \\
\hline 41 & 1,75 & 0,25 & 2,42 & 2,49 & 2,19 & 2,85 & 9,65 & 538 & 604,28 & 578,83 & 12,32 & 7,59 \\
\hline 41 & 0,75 & 0,25 & 2,08 & 2,33 & 2,54 & 12,21 & 22,13 & 394 & 435,39 & 434,42 & 10,50 & 10,26 \\
\hline 34,2 & 0,26 & 0,35 & 3,29 & 5,32 & 3,22 & 61,61 & 2,28 & 392 & 295,85 & 370,79 & 24,53 & 5,41 \\
\hline 34,2 & 1,25 & 0,175 & 2,04 & 1,83 & 1,84 & 10,26 & 9,69 & 479 & 434,63 & 453,04 & 9,26 & 5,42 \\
\hline 61 & 0,75 & 0,1 & 1,35 & 1,31 & 1,22 & 2,63 & 9,47 & 386 & 378,7 & 372,34 & 1,89 & 3,54 \\
\hline 61 & 1,75 & 0,1 & 1,67 & 1,45 & 1,18 & 13,21 & 29,17 & 503 & 520,62 & 641,21 & 3,50 & 27,48 \\
\hline 41 & 0,75 & 0,1 & 1 & 0,61 & 1,27 & 38,70 & 27,26 & 367 & 392,99 & 246,18 & 7,08 & 32,92 \\
\hline 41 & 1,75 & 0,1 & 0,91 & 1,35 & 1,10 & 48,68 & 20,35 & 432 & 420,88 & 488,46 & 2,57 & 13,07 \\
\hline 51 & 1,25 & 0,175 & 1,29 & 1,19 & 1,52 & 7,85 & 18,07 & 511 & 516,73 & 552,48 & 1,12 & 8,12 \\
\hline 51 & 0,41 & 0,175 & 2,25 & 1,11 & 1,76 & 50,57 & 21,91 & 392 & 343,26 & 322,83 & 12,43 & 17,65 \\
\hline \multicolumn{6}{|c|}{ Mean absolute percentage error (MAPE) } & 28,55 & 17,87 & & & & 8,64 & 9,93 \\
\hline
\end{tabular}

\section{CONCLUSION}

In this study, predictive models for $R a$ and $P$ were developed based on turning experiments using the RSM and ANN approach. The selected methodologies were compared to detect a methodology that gives better prediction results on the one hand and to discover which approach gives a precise upper power limit beyond which the vibration and deformation of the supporting parts lead to unwanted abruptly high roughness values.

The following conclusions can be enacted based on the results gained in this research:

- From analyses of ANOVA and ANN, it can be concluded that the feed rate greatly influences surface roughness. In comparison with feed rate, cutting speed and depth of cut have a negligible influence. Increase in feed rate results in poor surface roughness.

- Results of ANOVA and ANN for power differ. According to ANOVA, the dominant factor for power is the depth of cut and feed rate. On the other side, ANN shows that the most influenced factor is the depth of cut while feed rate and cutting speed have a similar impact.

- For surface roughness, ANN outperforms the prediction ability of RSM.
- For power, depending on the chosen criterion for evaluation of prediction ability of methods, results differ.

The error between the experimental values and predicted values shows that both models are, in most cases, not adequate to predict surface roughness when the power is greater than approximately $570 \mathrm{~W}$, followed by the greater values of cutting speed and feed rate. That gives us a specific dose of uncertainty in the correctness of results. The experimental results are unexpected which indicates that machine tools rigidity is too low on these power levels, which mostly results in unexpected surface roughness. Because of that, it is concluded that the power of the electric motor of $1100 \mathrm{~W}$ will be replaced with a smaller servo-electric motor of $750 \mathrm{~W}$ during the retrofitting process, which is cost-effective. Utilization of $1100 \mathrm{~W}$ servo motor or bigger will result, besides unexpected surface roughness, in strong vibrations and noise which is not adequate for the LF environment.

\section{Acknowledgements}

This work has been fully supported by the Unity Through Knowledge Fund (UKF), 1C My First Collaboration Grant, under the project 11/17 Development 
of integrative procedure for management of production and service improvement process.

\section{REFERENCES}

[1] Sangwan, K. S. \& Kant, G. (2017). Optimization of machining parameters for improving energy efficiency using integrated response surface methodology and genetic algorithm approach. Procedia CIRP, 61, 517-522. https://doi.org/10.1016/j.procir.2016.11.162

[2] Kant, G. \& Sangwan, K. S. (2014). Prediction and optimization of machining parameters for minimizing power consumption and surface roughness in machining. Journal of cleaner production, $\underline{83}$, 151-164. https://doi.org/10.1016/j.jclepro.2014.07.073

[3] Nouioua, M., Yallese, M. A., Khettabi, R., Belhadi, S., Bouhalais, M. L., \& Girardin, F. (2017). Investigation of the performance of the MQL, dry, and wet turning by response surface methodology (RSM) and artificial neural network (ANN). The International Journal of Advanced Manufacturing Technology, 93(5-8), 2485-2504. https://doi.org/10.1007/s00170-017-0589-2

[4] Gjeldum, N., Veža, I., \& Bilic, B. (2011). Prediction of the Material Removal Rates of Cylindrical Wire Electrical Discharge Turning Processes. Transactions of FAMENA, $35(1)$.

[5] Kamruzzaman, M., Rahman, S. S., Ashraf, M. Z. I., \& Dhar, N. R. (2017). Modeling of chip-tool interface temperature using response surface methodology and artificial neural network in HPC-assisted turning and tool life investigation. The International Journal of Advanced Manufacturing Technology, 90(5-8), 1547-1568. https://doi.org/10.1007/s00170-016-9467-6

[6] Das, B., Roy, S., Rai, R. N., \& Saha, S. C. (2015). Studies on effect of cutting parameters on surface roughness of al-cuTiC MMCs: an artificial neural network approach. Procedia Computer Science, 45, 745-752. https://doi.org/10.1016/j.procs.2015.03.145

[7] Chabbi, A., Yallese, M. A., Nouioua, M., Meddour, I., Mabrouki, T., \& Girardin, F. (2017). Modeling and optimization of turning process parameters during the cutting of polymer (POM C) based on RSM, ANN, and DF methods. The International Journal of Advanced Manufacturing Technology, 91(5-8), 2267-2290. https://doi.org/10.1007/s00170-016-9858-8

[8] Laouissi, A., Yallese, M. A., Belbah, A., Belhadi, S., \& Haddad, A. (2019). Investigation, modeling, and optimization of cutting parameters in turning of gray cast iron using coated and uncoated silicon nitride ceramic tools. Based on ANN, RSM, and GA optimization. TheInternational Journal of Advanced Manufacturing Technology, 101(1-4), 523-548. https://doi.org/10.1007/s00170-018-2931-8

[9] Camposeco-Negrete, C. (2015). Optimization of cutting parameters using Response Surface Method for minimizing energy consumption and maximizing cutting quality in turning of AISI 6061 T6 aluminum. Journal of cleaner production, 91, 109-117. https://doi.org/10.1016/j.jclepro.2014.12.017

[10] Tamang, S. K. \& Chandrasekaran, M. (2015). Modeling and optimization of parameters for minimizing surface roughness and tool wear in turning $\mathrm{Al} / \mathrm{SiCp} \mathrm{MMC}$, using conventional and soft computing techniques. Advances in Production Engineering \& Management, 10(2), 59. https://doi.org/10.14743/apem2015.2.192

[11] Kumar, R. \& Chauhan, S. (2015). Study on surface roughness measurement for turning of $\mathrm{Al} 7075 / 10 / \mathrm{SiCp}$ and Al 7075 hybrid composites by using response surface methodology (RSM) and artificial neural networking (ANN). Measurement, 65, 166-180.

https://doi.org/10.1016/j.measurement.2015.01.003

[12] Okokpujie, I. P., Ajayi, O. O., Afolalu, S. A., Abioye, A. A., Salawu, E. Y., \& Udo, M. (2018). Modeling and optimization of surface roughness in end milling of aluminium using least square approximation method and response surface methodology. International Journal of Mechanical Engineering and Technology (IJMET), 9(1), 587-600. http://www.iaeme.com/IJMET/issues.asp?

[13] Šarić, T., Šimunović, G., Vukelić, Đ., Šimunović, K., \& Lujić, R. (2018). Estimation of CNC Grinding Process Parameters Using Different Neural Networks. Tehnički vjesnik, 25(6), 1770-1775. https://doi.org/10.17559/TV-20180419095119

[14] Gjeldum, N., Mladineo, M., \& Veza, I. (2016). Transfer of model of innovative smart factory to Croatian economy using lean learning factory. Procedia CIRP, 54, 158-163. https://doi.org/10.1016/j.procir.2016.06.096

[15] Draper, N. R. \& Smith, H. (2014). Applied regression analysis, 326. John Wiley \& Sons. https://doi.org/10.1002/9781118625590

[16] Neşeli, S., Yaldız, S., \& Türkeş, E. (2011). Optimization of tool geometry parameters for turning operations based on the response surface methodology. Measurement, 44(3), 580587. https://doi.org/10.1016/j.measurement.2010.11.018

[17] Ranganathan, S., Senthilvelan, T., \& Sriram, G. (2010). Evaluation of machining parameters of hot turning of stainless steel (Type 316) by applying ANN and RSM. Materials and Manufacturing Processes, 25(10), 1131-1141. https://doi.org/10.1080/10426914.2010.489790.

[18] Sarıkaya, M. \& Güllü, A. (2014). Taguchi design and response surface methodology based analysis of machining parameters in CNC turning under MQL. Journal of Cleaner Production, 65, 604-616. https://doi.org/10.1016/j.jclepro.2013.08.040

[19] Vučina, D. (2005). Metode inženjerske numeričke optimizacije. FESB, Split.

[20] Karataş, C., Sozen, A., \& Dulek, E. (2009). Modelling of residual stresses in the shot peened material C-1020 by artificial neural network. Expert Systems with Applications, 36(2), 3514-3521. https://doi.org/10.1016/j.eswa.2008.02.012

[21] Šarić, T., Šimunović, G., Lujić, R., Šimunović, K., \& Antić, A. (2016). Use of soft computing technique for modelling and prediction of CNC grinding process. Technical Gazette, 23(4), 1123-1130. https://doi.org/10.17559/TV-20180419095119

[22] Madić, M., Marinković, V., \& Radovanović, M. (2012). Mathematical modeling and optimization of surface roughness in turning of polyamide based on artificial neural network. Mechanics, 18(5), 574-581. https://doi.org/10.5755/j01.mech.18.5.2701 


\section{Contact information:}

Amanda ALJINOVIĆ, mag. ing.

(Corresponding author)

Faculty of Electrical Engineering, Mechanical Engineering and Naval

Architecture,

Ruđera Boškovića 32, 21000 Split, Croatia

E-mail: amaljino@fesb.hr

Boženko BILIĆ, PhD, Full professor

Faculty of Electrical Engineering, Mechanical Engineering and Naval

Architecture,

Ruđera Boškovića 32, 21000 Split, Croatia

E-mail: bbilic@fesb.hr

Nikola GJELDUM, PhD, Assistant professo

Faculty of Electrical Engineering, Mechanical Engineering and Naval

Architecture

Ruđera Boškovića 32, 21000 Split, Croatia

E-mail: ngjeldum@fesb.hr

Marko MLADINEO, PhD, Assistant professor

Faculty of Electrical Engineering, Mechanical Engineering and Naval Architecture,

Ruđera Boškovića 32, 21000 Split, Croatia

E-mail: mmladine@fesb.hr 